\title{
Integrated Circuit Approach For Soft Switching In Boundary-Mode Buck Converter
}

\author{
Chu-Yi Chiang \\ Graduate Institute of Electronics Engineering \\ National Taiwan University \\ Taipei, Taiwan 10617 \\ binarystar@pelab5.ee.ntu.edu.tw
}

\author{
Chern-Lin Chen \\ Department of Electrical Engineering \\ \& Graduate Institute of Electronics Engineering \\ National Taiwan University \\ Taipei, Taiwan 10617 \\ clchen@cc.ee.ntu.edu.tw
}

\begin{abstract}
An integrated circuit approach is presented for ensuring soft switching operations in boundary-mode buck converters. This technique, accomplished by integrated circuitry, can automatically track the soft switching point without taking energy storage components into account. This control concept may be applied to boost and buck-boost converters as well. Circuit design and simulation results for an example circuit with $V_{\text {IN }} 5 \mathrm{~V}$ and $V_{\text {OUT }} 1.2 \mathrm{~V}$ are shown.
\end{abstract}

\section{I . INTRODUCTION}

In DC/DC switched-mode power supply, high frequency switching is usually desired to meet the demand of minimizing size and weight. However, high switching losses and noises keep the high switching frequency company. Soft switching techniques [1] have attracted lots of efforts for reducing switching loss and noise. Active clamp [2], asymmetrical half bridge [3-5], and phase-shift full bridge [6-8] etc., have been practically adopted in many commercial products. Soft switching is achieved by taking advantage of the resonance of transformer leakage inductance and power MOS parasitic capacitance. Selection of both of leakage inductance and MOS gating timing is crucial in control design. Managing uniformity of leakage inductance during mass production normally deserves great care.

Soft switching phenomenon under boundary mode operation in buck, boost, and buck-boost converters has been studied $[9,10]$. Boundary mode operation provides good stability and fast dynamics. Though the peak current and ripple voltage may go high, it is well suited for many low power applications. Benefits are simple control, easy design, and low cost.

In this paper, a new approach is presented for ensuring soft switching in boundary-mode buck converters. This technique, accomplished by integrated circuitry, can automatically track the optimum soft switching point. No further consideration of the parasitic/leakage components is required. This control concept can also be applied to boost and buck-boost converters.

\section{II.BUCK CONVERTER}

Fig. 1. shows the studied integrated buck converter. The power MOS can be either internal or external depending on the cost and thermal considerations. P-type power MOS is usually adopted for S1. If N-type power MOS is used, another charge pump circuit would be needed to drive the power MOS into the triode region. This increases not only the complexity of the circuit but the cost (large chip area of capacitor) of this control IC.

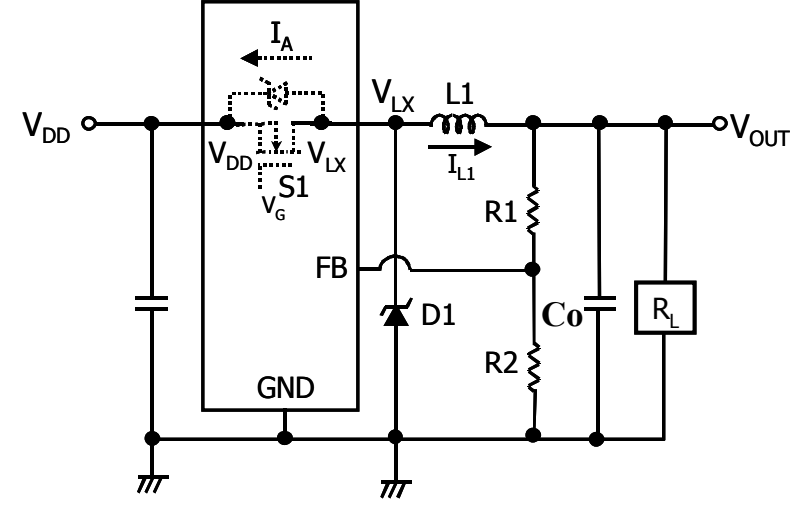

Fig. 1 The studied integrated buck converter

The anti-parallel diode may not exist because it can be eliminated through IC process. If it appears, for certain process, it conducts current $\mathrm{I}_{\mathrm{A}}$ when $\mathrm{V}_{\mathrm{LX}}$ is one diode-drop $\left(\mathrm{V}_{\mathrm{D}} \fallingdotseq 0.7 \mathrm{~V}\right)$ higher than $\mathrm{V}_{\mathrm{DD}}$. This happens when $\mathrm{V}_{\mathrm{OUT}}$ is higher than half of $\mathrm{V}_{\mathrm{DD}}$.

Power MOS S1 is turned on and off periodically and energy is thus transferred from $\mathrm{V}_{\mathrm{DD}}$ to the output. $\mathrm{S} 1$ is off when $\mathrm{V}_{\mathrm{G}}$ high and $\mathrm{S} 1$ on when $\mathrm{V}_{\mathrm{G}}$ low. Fig. 2 shows some important waveforms for a complete switching cycle when inductor current, $\mathrm{I}_{\mathrm{L} 1}$, works at boundary conduction mode. Freewheeling diode, D1, is used this study and synchronous rectifier may be utilized for enhancing efficiency.

During interval (1), $\mathrm{S} 1$ is on, $\mathrm{I}_{\mathrm{L} 1}$ flows directly from $\mathrm{V}_{\mathrm{DD}}$ to $\mathrm{V}_{\text {OUT }}$. $\mathrm{V}_{\mathrm{LX}}$ is slightly lower than $\mathrm{V}_{\mathrm{DD}}$ and $\mathrm{D} 1$ is off. $\mathrm{I}_{\mathrm{L} 1}$ increases proportional to $\left(\mathrm{V}_{\mathrm{DD}}-\mathrm{V}_{\mathrm{OUT}}\right)$.

During interval (2), S1 is off and $\mathrm{I}_{\mathrm{L} 1}$ flows through D1. $\mathrm{V}_{\mathrm{LX}}$ is at the level of GND minus $\mathrm{V}_{\mathrm{D} 1}(\sim 0.7 \mathrm{~V})$. $\mathrm{I}_{\mathrm{L} 1}$ decreases proportional to $\left(\mathrm{V}_{\mathrm{OUT}}+\mathrm{V}_{\mathrm{D} 1}\right)$.

At the end of interval (2), $\mathrm{I}_{\mathrm{L} 1}$ comes to zero. In interval (3), inductor L1 starts to oscillate with equivalent capacitance, $\mathrm{C}_{\mathrm{eq}}$, attached to node $\mathrm{V}_{\mathrm{LX}}$. Voltage at $\mathrm{V}_{\mathrm{LX}}$ then follows the resonance trajectory of $\mathrm{L} 1$ and $\mathrm{C}_{\mathrm{eq}}$. By the time that $\mathrm{S} 1$ turned on again, $\mathrm{V}_{\mathrm{LX}}$ can be of any value between $-\mathrm{V}_{\mathrm{D} 1}$ and $\mathrm{V}_{\text {OUT }}+\left(\mathrm{V}_{\text {OUT }}-\mathrm{V}_{\mathrm{D} 1}\right)=2 \mathrm{~V}_{\text {OUT }}-\mathrm{V}_{\mathrm{D} 1}$ through various switching techniques. The ending point of the cycle, when $\mathrm{S} 1$ switched on, is denoted " $\mathrm{V}_{\mathrm{LXS}}$ ". The peak of resonance is denoted as $\mathrm{V}_{\mathrm{LXZ}}$.

For each cycle, energy of $0.5^{*} \mathrm{C}_{\mathrm{eq}}\left(\mathrm{V}_{\mathrm{DD}}{ }^{2}-\mathrm{V}_{\mathrm{LXS}}{ }^{2}\right)$ in the equivalent capacitor attached to $\mathrm{V}_{\mathrm{LX}}$ is dissipated at the next turn-on. It may become a serious problem if converters are operated at high frequencies for the minimization of size and weight. Thus, designers try to turn on $\mathrm{S} 1$ when $\mathrm{V}_{\mathrm{LX}}$ moves as close to $\mathrm{V}_{\mathrm{DD}}$ as possible. The switching loss is minimized when S1 turned on at the peak of resonance, $\mathrm{V}_{\mathrm{LXZ}}$. 
(1)

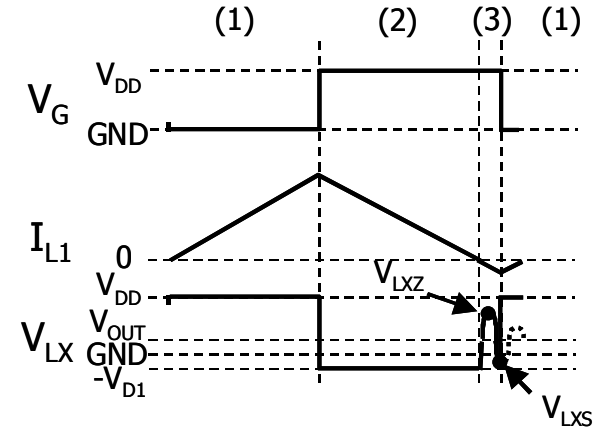

Fig. 2. Some key waveforms of boundary mode buck converter

\section{CONTROL OF SWITCHING TIMING}

Fig. 3 highlights the oscillation waveform $V_{L X}$ in interval (3). A peak detector for $V_{L X}$ detects the peak of $\mathrm{V}_{\mathrm{LX}}$ and sends a signal to turn on S1. Ideally, without circuit propagation delay, S1 can be turned on exactly at $\mathrm{V}_{\mathrm{LXz}}$. Yet this is not the case for real circuits. There is always propagation delay when signals travel. Therefore, $\mathrm{S} 1$ will be turned on when $\mathrm{V}_{\mathrm{LX}}$ equal to $\mathrm{V}_{\mathrm{LXZD}}$, shortly after $V_{\text {LXZ. }}$.

The time $\mathrm{V}_{\mathrm{LX}}$ propagating from $\mathrm{V}_{\mathrm{LXZ}}$ to $\mathrm{V}_{\mathrm{LXZD}}$, denoted as $\triangle t_{D}$, includes all propagation delay in peak detector and other logic circuits. It is defined as the time between $V_{L X}$ reaching its maximum and power MOS S1 being just turned on. If, in steady sate, we turn on $\mathrm{S} 1$ at $\mathrm{V}_{\mathrm{LXA}}, \triangle \mathrm{t}_{\mathrm{D}}$ before $\mathrm{V}_{\mathrm{LXZ}}, \mathrm{S} 1$ will be turned on exactly at $\mathrm{V}_{\mathrm{Lxz}}$. This can be done by sampling $\mathrm{V}_{\mathrm{LXZD}}$, holding it as threshold voltage $\mathrm{V}_{\mathrm{LXZA}}$, comparing it with $\mathrm{V}_{\mathrm{LX}}$ when oscillating in interval (3).

Functional diagram of the proposed control approach is shown in Fig. 4. Inside the dotted lines are internal elements. Integrated P-type power MOS S1 is used. By voltage divider, pin FB senses the condition of $\mathrm{V}_{\text {OUT }}$, that is, at light or heavy load. Block 'Switching "Off"' sends out the turn-off signal to S1. It is assumed that the converter is designed in voltage mode control. The off signal has no effect on soft switching and will be neglected here. Block 'Switching "On"' determines the best timing to turn on S1. SR-latch is composed of NAND gates and is shown in Fig. 5.

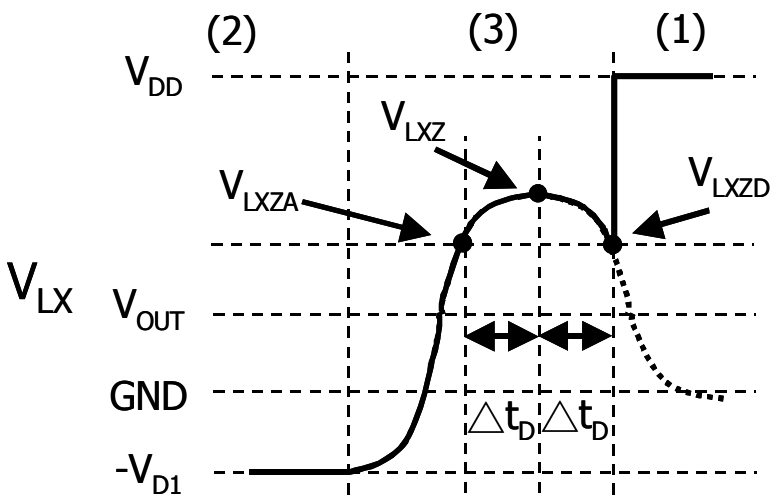

Fig. 3. Waveform of $V_{L X}$ while oscillating

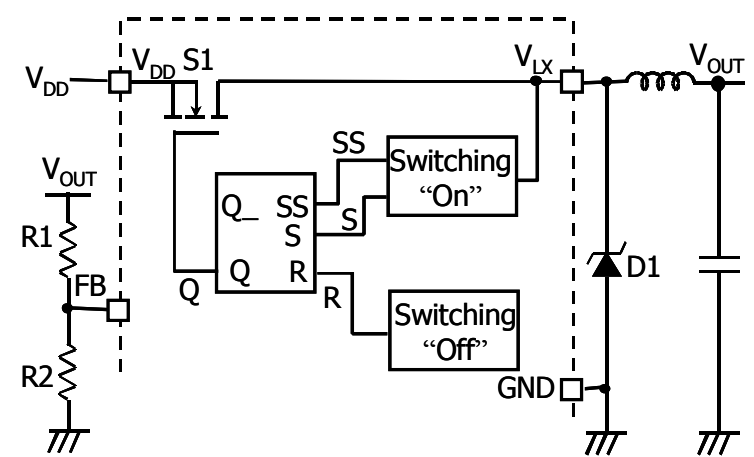

Fig. 4. Functional diagram of proposed control

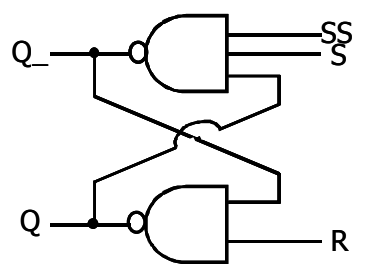

Fig. 5. 3-input NAND gate SR-latch

Unlike typical NAND gate SR-latch, there are three inputs in one NAND gate. When S, SS (abbreviation of soft switching here) and $\mathrm{R}$ are all equal to "1", Q and $\mathrm{Q}$ (means QBAR, the complement of Q) remains its original state. If $\mathrm{S}$ or $\mathrm{SS}=$ "0" and $\mathrm{R}=$ " 1 ", $\mathrm{Q}$ will be switched to " 1 " first and then $\mathrm{Q}$ to "0" no matter what the original states are. If $\mathrm{S}$ and SS both are "1" and $\mathrm{R}=$ " 0 ", $\mathrm{Q}$ will be switched to "1" and Q to "0" later.

Block 'Switching "On"” consists of two parts: "Peak Detector" and "Soft Switching", as shown in Fig. 6. As long as $\mathrm{V}_{\mathrm{LX}}$ is lower than, say, $0.2 \mathrm{~V}$ here, both of them will be shut down to avoid malfunction.

In interval (3) and $\mathrm{V}_{\mathrm{LX}}$ greater than $0.2 \mathrm{~V}$, "Peak Detector" is activated. When it detects a peak in $V_{L X}$ waveform, it sends a "0" signal to node "S", then $\mathrm{Q}$ will be " 0 " and $\mathrm{S} 1$ is thus turned on. Because of circuit propagation delay, $\mathrm{Q}$ will be " 0 " when $\mathrm{V}_{\mathrm{LX}}$ is equal to $V_{\text {LXZD. }}$. In steady state, both sub-blocks work. "Soft Switching" samples and holds $\mathrm{V}_{\mathrm{LXZD}}$ (as $\mathrm{V}_{\mathrm{LXZA}}$ ). It compares $\mathrm{V}_{\mathrm{LX}}$ and this stored value and sends a "0" to node "SS". Then, Q will be "0" (S1 turned on) when VLX equal to $V_{\text {LXz. }}$. Soft switching is thus accomplished. "Peak Detector" will have no effect in this state because when a peak $\left(\mathrm{V}_{\mathrm{LXz}}\right)$ detected, $\mathrm{S} 1$ has been changed to another state.

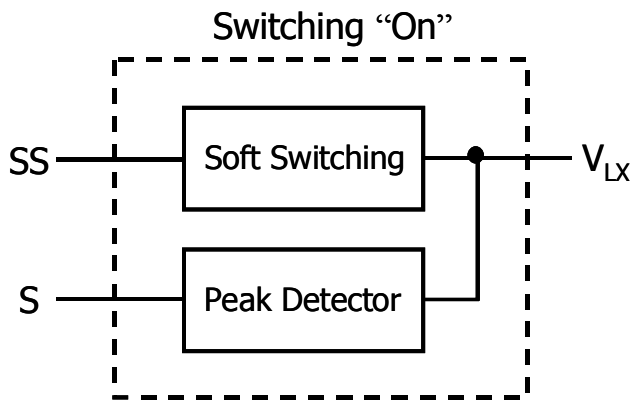

Fig. 6. .Switching "On"' block 
Circuits of "Peak Detector" are shown in Fig. 7. It is made up of two comparators, two OP's, two reset PMOS's, one NMOS, one capacitor, and one NAND gate SR-latch. A typical peak detector is formed of one OP, one PMOS and one capacitor, as shown in Fig. 8. $\mathrm{V}_{\mathrm{LX}}$ is buffered by a negative-feedback OP1 so that OP1's output $\mathrm{V}_{\text {LXP }}$ will not go under ground level and have enhanced driving ability. Rail-to-rail OP's and PMOS-input comparators are used here and shown in Fig. 9 and Fig. 10, respectively.

We assume that initially $\mathrm{S}=$ " 0 ", $\mathrm{R}=$ ="1", and then $\mathrm{Q}=$ " 0 ". Therefore, $\mathrm{S} 1$ is on and $\mathrm{V}_{\mathrm{LX}}$ is pulled up to almost $\mathrm{V}_{\mathrm{DD}}$. After that, " $\mathrm{S}$ " is switched back to " 1 " and sub-block "Peak Detector" can do nothing about the state of S1. Meanwhile, $\mathrm{V}_{\mathrm{LXP}}$ is equal to $\mathrm{V}_{\mathrm{DD}}$ and output of CP2 is high. Thus QOP is " 0 " and QOP " 1 ". M1 and M3 is turned on and output of OP2 is pulled up to $\mathrm{V}_{\mathrm{DD}}$. M2 is thus off and capacitor $\mathrm{C} 1$ is fully discharged (reset).

When $\mathrm{S} 1$ is off $\left(\mathrm{Q}=\right.$ " 1 "), voltage of $\mathrm{V}_{\mathrm{LX}}$ goes down to one diode drop below ground level. Because of the limited output swing of buffer, $\mathrm{V}_{\mathrm{LXP}}$ tracks $\mathrm{V}_{\mathrm{LX}}$ and stops at ground level as voltage of $\mathrm{V}_{\mathrm{LX}}$ is under ground voltage. At this moment, S remains at " 1 " because of the hysteresis of comparator CP1. The output of the other comparator CP2 is at " 0 " state and NAND gate SR-latch is "reset". Thus QOP is " 1 " and QOP_ "0", making M1 and M3 off and the typical peak detector activated. As energy in L1 runs out, it starts to oscillate with Ceq. As $V_{L X}$ reaches its peak, the typical peak detector stores this value as $\mathrm{V}_{\mathrm{LXZ}}$ on $\mathrm{C} 1$. Then $\mathrm{V}_{\mathrm{LX}}$ moves down and is compared to $\mathrm{V}_{\mathrm{LXZ}}$ through CP1. Consequently, a peak is detected and $\mathrm{S}$ is " 0 " again ( $\mathrm{S} 1$ on) when $\mathrm{V}_{\mathrm{LX}}$ reaches $\mathrm{V}_{\mathrm{LXZD}}$.

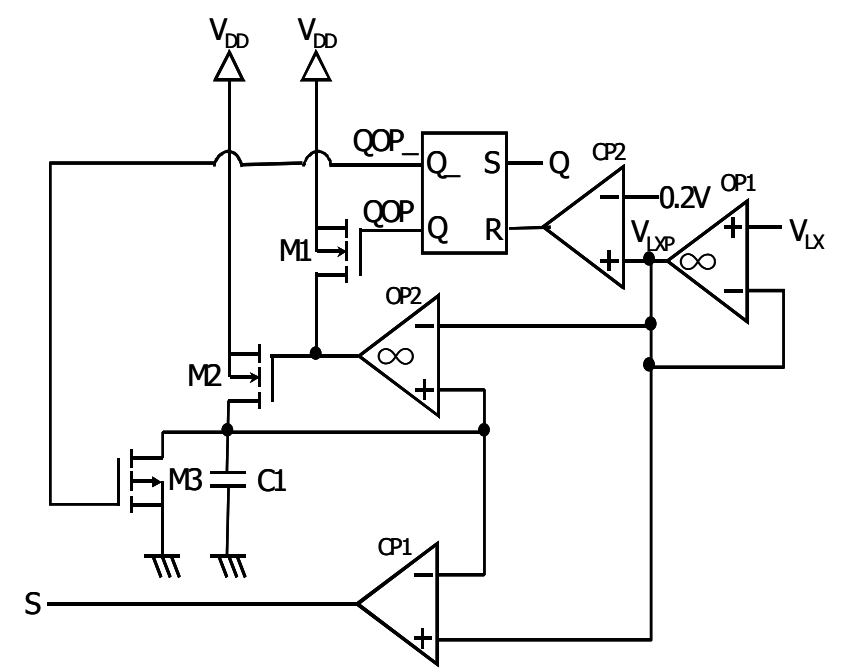

Fig. 7. Circuits of "Peak Detector"

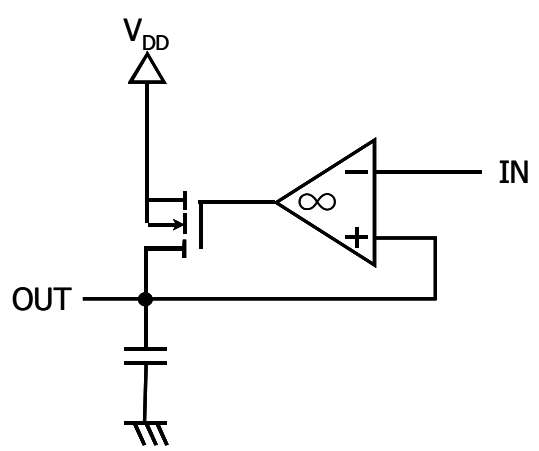

Fig. 8. Typical peak detector
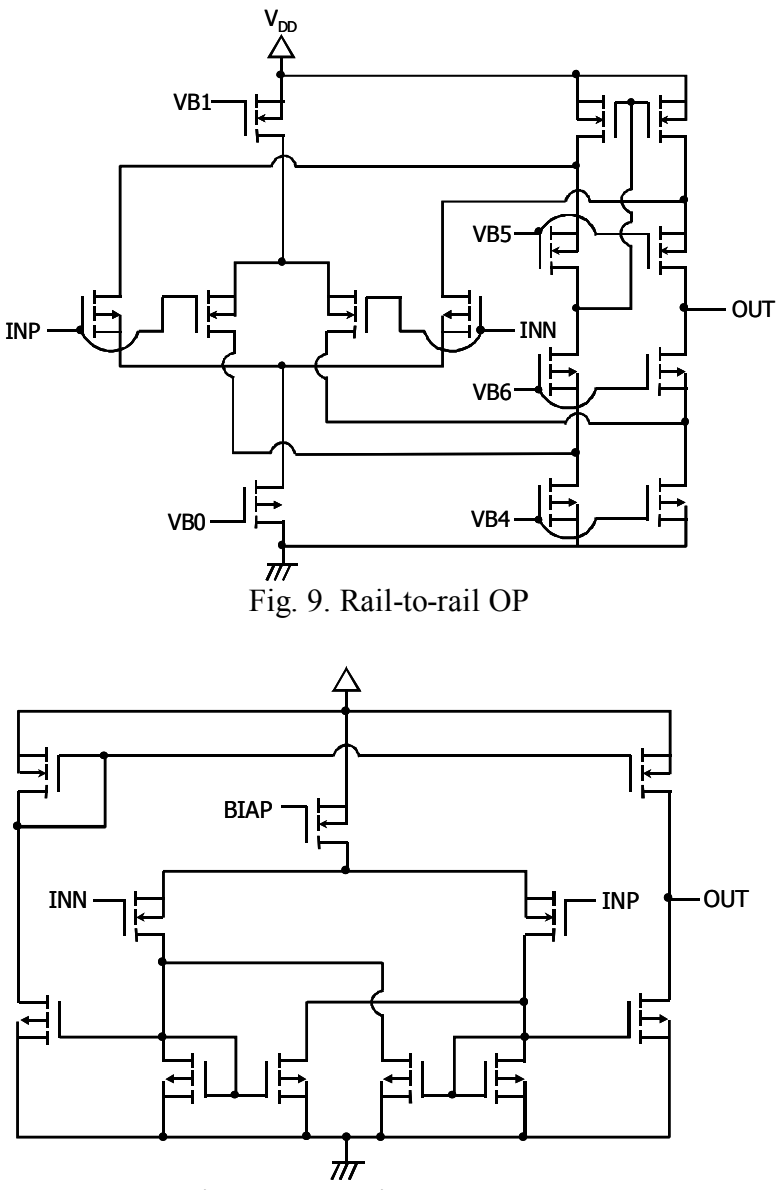

Fig. 10 PMOS-input comparator

Circuits of "Soft Switching" are shown in Fig. 11. It consists of one sample and hold $(\mathrm{S} / \mathrm{H})$ circuit (enclosed by dotted lines), one error amplifier OP1 compensated with one capacitor $\mathrm{C} 1$, two comparators, and one pulling PMOS M4. "SS Sampling Logic" means "soft switching sampling logic". Its output, SSSS (Soft Switching Sampling Switch) controls the sampling switch of $\mathrm{S} / \mathrm{H}$ circuit.

$\mathrm{S} / \mathrm{H}$ circuit is composed of one buffer OP2, one sampling switch and one sampling capacitor C2. We use transmission gate as sampling switch so that no data would be lost during sampling. Here, we define that transmission gate is "On" when the applied control voltage is $\mathrm{V}_{\mathrm{DD}}$ (" 1 " state).

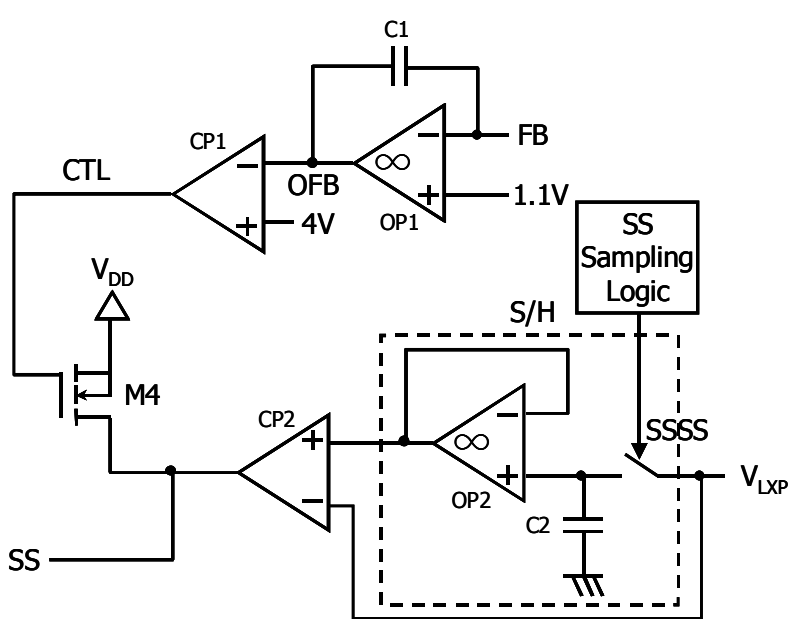

Fig. 11. Circuits of "Soft Switching" 
The $1.1 \mathrm{~V}$ reference voltage comes from band-gap reference circuit and $4 \mathrm{~V}$ reference voltage is obtained by voltage divider.

During transient, $\mathrm{V}_{\text {OUT }}$ is below its desired value and $\mathrm{FB}$ below $1.1 \mathrm{~V}$, too. The difference between them is further amplified by the error amplifier and its output OFB is pulled up to $\mathrm{V}_{\mathrm{DD}}$, say, $5 \mathrm{~V}$ here. Then, $\mathrm{CTL}$ is at low, state through CP1 and M4 is on. Thus, SS is equal to " 1 " and will not affect the state of S1. Sample and hold circuit samples nothing because soft switching sampling switch "SSSS" is off.

As long as buck converter enters steady state, CTL is high and M4 off. Sample and hold circuit works at this moment. It tracks $V_{\mathrm{LXP}}$ and shot down the sampling switch when $V_{L X}$ travels to $V_{L X D}$. Voltage of $V_{\text {LXD }}$ is thus held on $\mathrm{C} 2$ and compared to $\mathrm{V}_{\mathrm{LXP}}$ for later cycles. Soft switching is accomplished through this way.

"SS Sampling Logic" is mainly composed of one falling-edge triggered flip-flop. Some other logic gates are added, as shown in Fig 12.

During transient, CTL is low and so is SSSS. STE remains at the original state "1". Therefore, sampling switch is off and $\mathrm{S} / \mathrm{H}$ does not work. Inputs of the flip-flop are disconnected from the master latch.

If steady state entered, CTL is switched to high state and inputs of the flip-flop change to the other state (" 0 " at the top and "1" at the bottom). For buck converter, if power MOS S1 is on $(\mathrm{Q}=$ " 0 "), SSSS is " 0 " and nothing sampled at this time. Later, $\mathrm{S} 1$ is turned off $(\mathrm{Q}=$ " 1 "), and SSSS is at high state. Data is allowed to enter the first latch and stopped by the second latch. STE is thus at the same state "1". Meanwhile, sample and hold circuit starts sampling the voltage of $V_{\text {LXP. }}$. After energy run-out of L1, oscillation occurs and sub-block "Peak Detector" detects a peak of $\mathrm{V}_{\mathrm{LX}}$, and makes $\mathrm{S}$ " 0 " state. Later, $\mathrm{S} 1$ is turned on (Q=" 0 ") when value of $V_{L X}$ equal to $V_{L X D}$. At this time, SSSS is changed to low state and value of $\mathrm{V}_{\mathrm{LXD}}$ is held on $\mathrm{C} 2$ in $\mathrm{S} / \mathrm{H}$ circuit as the threshold voltage for coming cycles. SSSS will not be high again until CTL is switched back to "0" to ensure that sub-block "Soft Switching" functions well.

\section{Falling Edgetriggered Hip-flop}

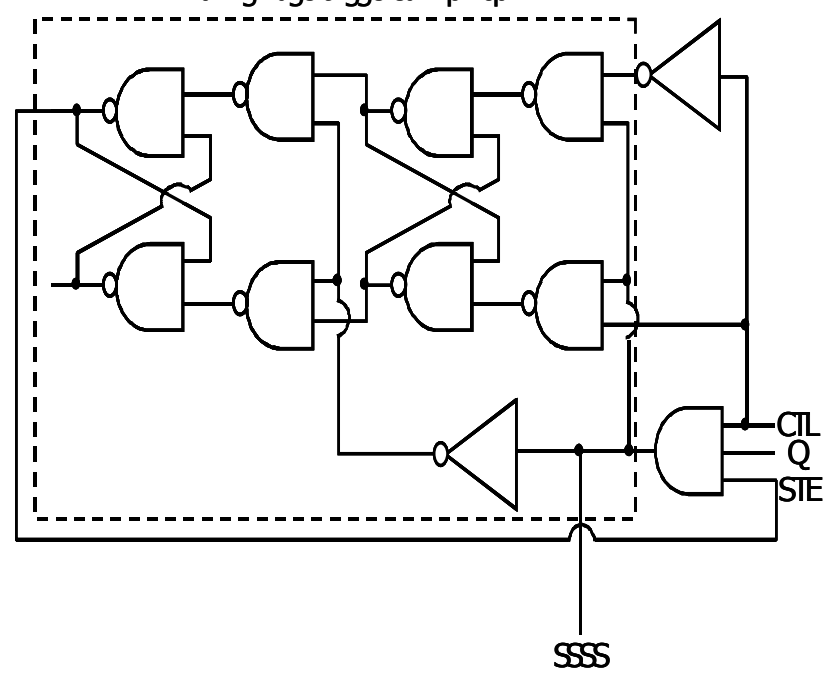

Fig. 12. "SS Sampling Logic"

\section{SIMULATION RESULTS}

The speed of "Peak Detector" is crucial in the system performance. A $10 \mathrm{MHz}$ sinusoidal signal with a DC level of $2.5 \mathrm{~V}$ and increasing amplitude is applied to its input. Simulation results for sub-block "Peak Detector" is shown in Fig. 13. The designed peak detector functions well at such a high frequency.

Shown in Fig. 14 are simulations for the complete system with $\mathrm{L} 1=10 \mathrm{uH}, \mathrm{Co}=47 \mathrm{uF}$, and equivalent $\mathrm{V}_{\mathrm{OUT}}$ at FB is designed as $1.2 \mathrm{~V}$. Fig. 14(a) shows the waveforms of the whole system in transient state. $\mathrm{V}_{\text {OUT }}$ is $0.684 \mathrm{~V}, \mathrm{~V}_{\mathrm{LX}}$ $2.09 \mathrm{~V}$ and $\mathrm{V}_{\mathrm{LXS}} 1.90 \mathrm{~V}$. Difference between $\mathrm{V}_{\mathrm{LX}}$ and $\mathrm{V}_{\mathrm{LXS}}$ is $0.19 \mathrm{~V}$. In Fig. 14(b), waveforms in steady state are shown. $\mathrm{V}_{\mathrm{OUT}}$ is $1.2 \mathrm{~V}, \mathrm{~V}_{\mathrm{LX}} 3.26 \mathrm{~V}$ and $\mathrm{V}_{\mathrm{LXS}} 3.05 \mathrm{~V}$. Difference between them is $0.21 \mathrm{~V}$, almost equal to that in Fig 14. (a) (transient state). It can be figured out that the time from $V_{L X}$ reaching its highest point to $S 1$ being turned on is almost equal in transient and steady state. Fig. 14 (c) shows the waveforms of the whole system in steady state with soft switching activated. $\mathrm{V}_{\text {OUT }}$ is $1.2 \mathrm{~V}, \mathrm{~V}_{\mathrm{LX}}$ $3.26 \mathrm{~V}$ and $\mathrm{V}_{\mathrm{LXS}} 3.26 \mathrm{~V}$. It can be seen that if "Soft Switching" is not activated, $\mathrm{S} 1$ will be turned on when $\mathrm{V}_{\mathrm{LX}}$ moves to $\mathrm{V}_{\mathrm{LXD}}$, about $0.2 \mathrm{~V}$ lower than its peak value $\mathrm{V}_{\mathrm{LXZ}}$. If soft switching activated, $\mathrm{S} 1$ is turned on exactly when $\mathrm{V}_{\mathrm{LX}}$ reaches its highest point. In this example, $\mathrm{V}_{\mathrm{LXZ}}=3.26 \mathrm{~V}$. This soft switching technique does work properly.

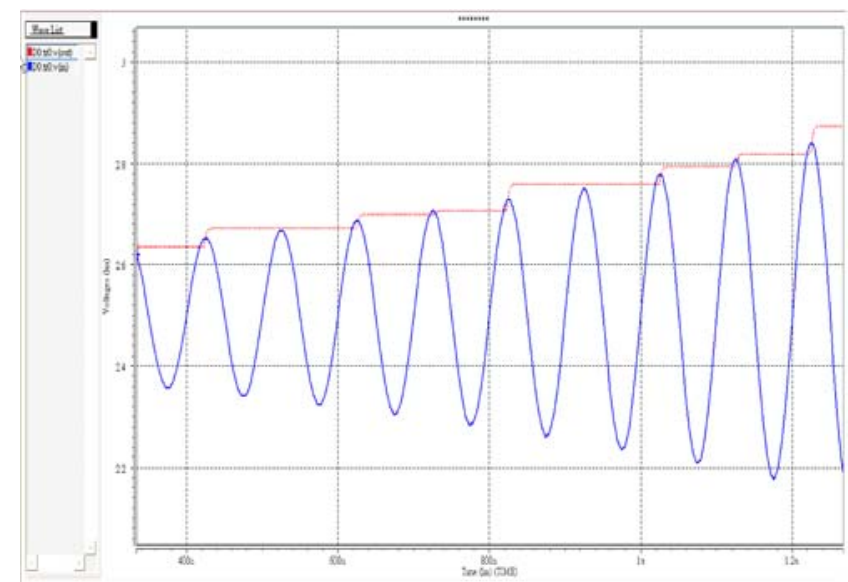

Fig. 13. Input and output waveform of "Peak Detector"

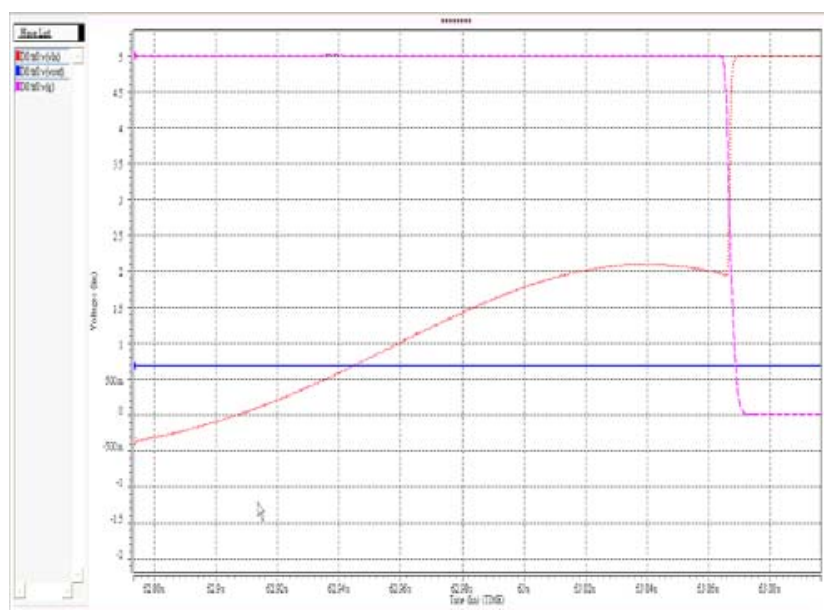

(a) Transient state

$\mathrm{V}_{\text {OUT }}=0.684 \mathrm{~V}, \mathrm{~V}_{\text {LXZ }}=2.09 \mathrm{~V}, \mathrm{~V}_{\text {LXS }}=\mathrm{V}_{\mathrm{LXD}}=1.90 \mathrm{~V}$ 


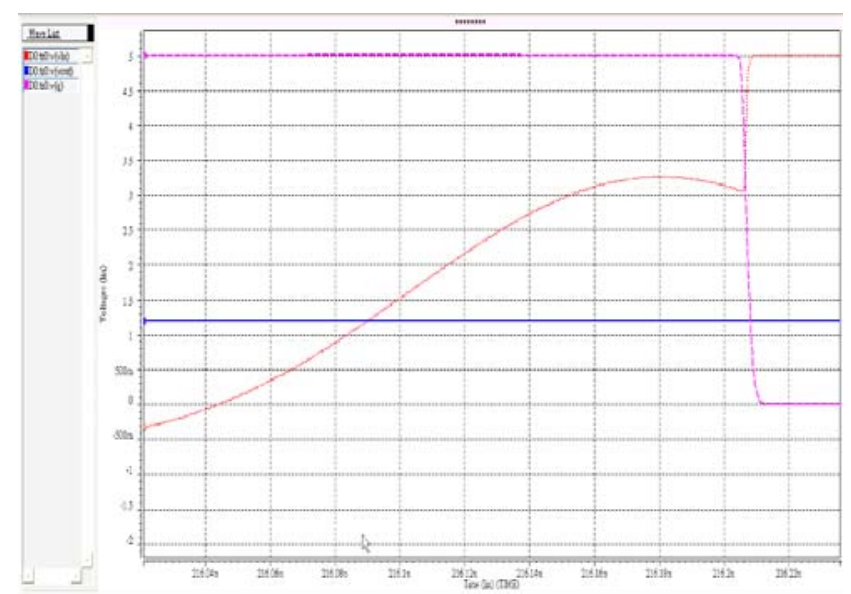

(b) Steady state

$\mathrm{V}_{\mathrm{OUT}}=1.2 \mathrm{~V}, \mathrm{~V}_{\mathrm{LXZ}}=3.26 \mathrm{~V}, \mathrm{~V}_{\mathrm{LXS}}=\mathrm{V}_{\mathrm{LXD}}=3.05 \mathrm{~V}$

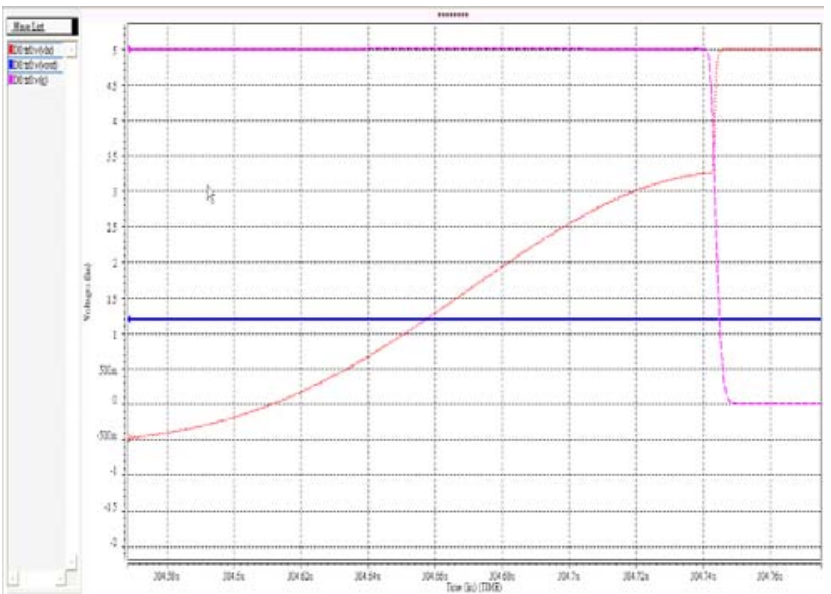

(c) "Soft Switching" activated

$\mathrm{V}_{\text {OUT }}=1.2 \mathrm{~V}, \mathrm{~V}_{\mathrm{LXZ}}=3.26 \mathrm{~V}, \mathrm{~V}_{\mathrm{LXS}}=3.26 \mathrm{~V}$

Fig. 14. Gating signal and $V_{L X}$ waveforms

\section{CONCLUSIONS}

In this paper, a new soft-switching control technique for boundary-mode buck converters is presented. Operation principle is analyzed and integrated control circuit design is performed. The whole integrated circuit system is under fabrication. Hspice simulation results are shown to illustrate the effectiveness of the proposed control concept.

The designed integrated circuit controller with the proposed control approach is able to compensate the circuit propagation delay and automatically track the optimum switching timing. The smart controller guarantees soft switching for boundary mode buck converters. Similar concepts apply well to boost and buck-boost converters. Power supply design will become simpler with this kind of smart IC controller.

\section{REFFERENCES}

[1] A. I. Pressman, Switching Mode Power Supply Design, $2^{\text {nd }}$ ed., pp. 488-489, 1999.

[2] Q. M. Li, F. C. Lee, M. M. Jovanovic, "Large-signal transient analysis of forward converter with active-clamp reset," IEEE Trans. Power Electronics, Vol.17, No.1, 2002.

[3] S. Korotkov, V. Meleshin, A. Nemchinov, S. Fraidlin, "Small-signal modeling of soft-switched asymmetrical half-bridge DC/DC converter," IEEE Applied Power Electronics Conference, pp.5-9, 1995.

[4] T. M. Chen, C. L. Chen, "Analysis and design of asymmetrical half bridge flyback converter," IEE Proc.- Electric Power Applications, Vol.149, No.6, pp.433-440, 2002.

[5] Y. H. Leu, C. L. Chen, "Improved asymmetrical half-bridge converter using a tapped output inductor filter," IEE Proc.- Electric Power Applications, Vol.150, No.4, pp.417-424, 2003.

[6] X. Wu, J. M. Zhang, Z. Qian, “Optimum design considerations for a high efficiency ZVS full bridge DC-DC converter," INTELEC, pp.338-344, 2004.

[7] Y. Jang, M. M. Jovanovic, "A new family of full-bridge ZVS converters," IEEE Trans. Power Electronics, Vol.19, No.3, pp.701-708, 2004.

[8] S. Y. Lin, C. L. Chen, "On the leading leg transition of phase-shifted ZVS-FB converters," IEEE Trans. Industrial Electronics, Vol.45, No.4, pp.677-679, 1998.

[9] C. J. Tseng, C. L. Chen, "A passive lossless snubber cell for non-isolated PWM DC/DC converters," IEEE Trans. Industrial Electronics, Vol.45, No.4, pp.593-601, Aug. 1998.

[10] Z. Yingqi, P. C. Sen, "A new soft switching technique for buck, boost and buck-boost converters," IEEE Industry Application Society Meeting, Vol.4, pp.13-18, 2002. 